\title{
Cellulolytic Enzymes Production via Solid-State Fermentation: Effect of Pretreatment Methods on Physicochemical Characteristics of Substrate
}

\author{
Khushal Brijwani and Praveen V. Vadlani \\ Bioprocessing Laboratory, 201 Shellenberger Hall, Department of Grain Science and Industry, Kansas State University, \\ Manhattan, KS 66506, USA \\ Correspondence should be addressed to Praveen V. Vadlani, vadlani@ksu.edu
}

Received 9 December 2010; Revised 18 February 2011; Accepted 31 March 2011

Academic Editor: Mohamed Farid

Copyright ( $) 2011$ K. Brijwani and P. V. Vadlani. This is an open access article distributed under the Creative Commons Attribution License, which permits unrestricted use, distribution, and reproduction in any medium, provided the original work is properly cited.

\begin{abstract}
We investigated the effect of pretreatment on the physicochemical characteristics—crystallinity, bed porosity, and volumetric specific surface of soybean hulls and production of cellulolytic enzymes in solid-state fermentation of Trichoderma reesei and Aspergillus oryzae cultures. Mild acid and alkali and steam pretreatments significantly increased crystallinity and bed porosity without significant change inholocellulosic composition of substrate. Crystalline and porous steam-pretreated soybean hulls inoculated with $T$. reesei culture had 4 filter paper units (FPU)/g-ds, $0.6 \mathrm{IU} / \mathrm{g}$-ds $\beta$-glucosidase, and $45 \mathrm{IU} / \mathrm{g}$-ds endocellulase, whereas untreated hulls had $0.75 \mathrm{FPU} / \mathrm{g}$-ds, $0.06 \mathrm{IU} / \mathrm{g}$-ds $\beta$-glucosidase, and $7.29 \mathrm{IU} / \mathrm{g}$-ds endocellulase enzyme activities. In A. oryzae steam-pretreated soybean hulls had $47.10 \mathrm{IU} / \mathrm{g}$-ds endocellulase compared to $30.82 \mathrm{IU} / \mathrm{g}$-ds in untreated soybean hulls. Generalized linear statistical model fitted to enzyme activity data showed that effects of physicochemical characteristics on enzymes production were both culture and enzyme specific. The paper shows a correlation between substrate physicochemical properties and enzyme production.
\end{abstract}

\section{Introduction}

With increasing emphasis on bio-based fuels and chemicals, the cellulase market is expected to increase dramatically [1]. To create a sustainable bioeconomy, cellulases need to be produced cost-effectively and possess excellent biocatalytic properties [2]. Solid-state fermentation (SSF) offers a lowcost alternative for producing cellulases using natural polymers derived from agroindustrial residues $[3,4]$.

SSF is defined as a discrete solid phase in which microorganisms grow on the surface of moist particles as well as inside and between them. The space between particles is occupied by a continuous gas phase [5]. Gas phase in SSF is strongly affected by the size, shape, and tortuosity of a network of gas-filled pores. The air- or gas-filled pores are referred to as bed porosity, which is defined as the volume of gas contained in the system at any given time (void fraction) [6]. Availability of spaces between particles ensures availability of oxygen that improves enzyme production in aerobic fungal cultures [7-9]. Chutmanop et al. [10] showed that by blending rice bran with wheat bran resulted in substantial improvement in the morphology of rice bran which improved protease production during solid-state culturing of A. oryzae. The increase in bed porosity of the substrate could be the reason behind improved production; however, no attempts were made to measure bed porosity to show its relationship to enzyme production. Several authors in the past have suggested the merits of open porous solid beds but no explicit investigation has been conducted yet that relates bed porosity with enzyme production in SSF. In industrial scale SSF processes, bed porosity is essential but not sufficient for complete process control. Other parameters, such as microbial cell physiology, composition of the solid substrate, and substrate reactivity also could influence the productivity of the process $[11,12]$.

Substrate reactivity, especially in case of cellulosic substrates, is influenced by physicochemical characteristics of 
the substrate at different levels. At microfibril level it is crystallinity of cellulose, and at fiber level it is specific surface area (characterizing pore size or degree of swelling) [13-15]. The increase in cellulase reactivity due to increase in specific surface area is attributed to the creation of surface openings or internal slits, voids, or spaces, by the removal of cell wall components, that enhances the direct physical contact between the enzymes and the substrate [16]. During growth on complex substrates, propagation of fungal mycelium occurs via production of enzymes that drive hydrolytic reactions. The hydrolytic reactions are responsible for generation of soluble sugars that facilitate fungal growth. It has been proposed that the hydrolysis occurs efficiently when the pores within the substrate are large enough to accommodate both large and small enzyme components to maintain the synergistic action of the enzyme system $[14,17,18]$. On the other hand, reduced surface area impedes this synergistic action.

Crystalline cellulose digestion requires concerted action of exo- and endoglucanases. The crystalline nature of the carbon source used to induce cellulolytic expression in many species of fungi significantly influences the hydrolytic potential of the enzyme preparation [19]. Evans et al. [20] showed that crystalline-cotton-induced cellulolytic complex derived from submerged $T$. reesei cultures exhibited higher potential in hydrolyzing crystalline cellulose than Solka-Floc-induced cellulases. Fungi growing on complex cellulosic substrates are prone to catabolite repression by glucose [21]. The extent of catabolite repression depends on the rate of glucose formation, which in turn depends on the secretion of enzymes that degrade cellulose. Fan et al. [22, 23], and, more recently, Ciolacu et al. [24] and Hall et al. [25] have shown that the rate of cellulose degradation is dependent on crystallinity of the cellulosic substrate. In other words, crystallinity of cellulosic sample could alter not only the quality of enzymes (the proportion of various activities with cellulolytic enzyme complex) but also the quantity of enzymes produced. Thus, studies delineating the effects of crystallinity on enzyme production in SSF are of significant interest.

The growth of fungi in natural substrates is usually slow and this limitation must be overcome by suitable mechanical and chemical pretreatment of the raw substrate [26]. However, pretreatments are known to induce structural changes in cellulosic substrates, which could alter the physicochemical properties of the substrate [2]. The effect of pretreatment methods on physicochemical characteristics of substrate and its repercussions on cellulolytic enzyme productivity in fungal solid-state fermentation has not been investigated so far, which is evident from the recent reviews on $\operatorname{SSF}[3,27]$. An in-depth understanding of the role of physicochemical characteristics of substrate on cellulase production in SSF would provide a framework for comprehensive analysis of critical design issues that should facilitate cellulase production with enhanced biocatalysis.

The present study aimed to determine the role of pretreatment techniques in altering the physicochemical characteristics—bed porosity, volumetric specific surface, and crystallinity of solid-state substrate. In addition, the effect of change in physicochemical attributes on enzyme production in fungal solid-state fermentation was studied with respect to type of fungal species and different cellulolytic enzyme activities. The pretreatments were carefully chosen to limit the effect on the chemical compositional changes of solid substrate, which would otherwise diminish the role of physicochemical attributes. Since crystallinity is critical to this study, a new method of measuring crystallinity of complex cellulosic substrate was also discussed.

\section{Materials and Methods}

2.1. Sample Preparation. Untreated ground soybean hulls (purchased from Archer Daniels Midland, Salina, KS, USA), herein referred to as native soybean hulls, had a geometric mean diameter, $d_{\mathrm{gw}}$, of $0.61 \pm 0.002 \mathrm{~mm}$. Native soybean hulls were subjected to four different treatments before being used for production of the cellulolytic enzyme system: (1) steam pretreatment, in which a $5 \%(\mathrm{w} / \mathrm{v})$ slurry of soybean hulls in distilled water was pressure cooked at $121^{\circ} \mathrm{C}$ for $60 \mathrm{~min}$; (2) hydrochloric acid pretreatment, in which a $5 \%$ $(\mathrm{w} / \mathrm{v})$ slurry of soybean hulls in $1 \mathrm{~N} \mathrm{HCl}$ was kept on a gyratory shaker $(150 \mathrm{rpm})$ for $24 \mathrm{~h}$ at ambient temperature; (3) sulfuric acid pretreatment, in which a $5 \%(\mathrm{w} / \mathrm{v})$ slurry of soybean hulls in $1 \mathrm{~N} \mathrm{H}_{2} \mathrm{SO}_{4}$ was kept on a gyratory shaker $(150 \mathrm{rpm})$ for $24 \mathrm{~h}$ at ambient temperature (4) sodium hydroxide pretreatment, in which a $5 \%(\mathrm{w} / \mathrm{v})$ slurry of soybean hulls in $1 \mathrm{~N} \mathrm{NaOH}$ was kept on a gyratory shaker (150 rpm) for $24 \mathrm{~h}$ at ambient temperature. After acid and alkali pretreatments, treated soybean hulls were collected by filtration and extensively washed with distilled water. The $\mathrm{pH}$ was adjusted to approximately 5.5. Steam-pretreated soybean hulls were washed once. All treated substrates were dried overnight at $45^{\circ} \mathrm{C}$ in a forced-draft oven (Fisher Scientific, USA). Dried substrates were used for compositional analysis, analysis of physicochemical characteristics, and production of enzymes. Treatments were performed in quadruplets.

\subsection{SSF for Cellulolytic Enzyme System Production in Native} and Pretreated Soybean Hulls. Two fungal cultures T. reesei (ATCC 26921) and A. oryzae (ATCC 12892) were used for SSF of native and pretreated soybean hulls. Cultures were used as both mono and mixed $(1: 1)$. Native and pretreated dried soybean hulls $(5 \mathrm{~g})$ were adjusted to $70 \%$ (wet basis) moisture content $(\mathrm{mc})$ by using Mandels media [28] of pH 5 and were sterilized in a vertical sterilizer $\left(121^{\circ} \mathrm{C} / 15 \mathrm{psi}\right.$ gauge $)$ for 30 minutes. Cultures were added as spore suspensions $\left(10^{8}\right.$ spores $/ \mathrm{mL}$-suspension) at the loading of $0.1 \mathrm{~mL}$ per gram dry substrate. The propagation, maintenance, and generation of spore suspensions are described in [29]. Flasks containing two cultures in the ratio of $1: 1$ were labeled as mixed. Flasks were incubated for 5 days at $30^{\circ} \mathrm{C}$. The conditions of temperature, $\mathrm{pH}$, moisture $(70 \%)$, and incubation days of the SSF process used in this study were optimized previously [29]. Following incubation, enzymes were extracted and analyzed per section analytical methods. 
2.3. Analysis of Physical Parameters: Bed Porosity. Porosity $(\varepsilon)$ of the samples was computed from the values of true density and bulk density by using the relationship described in [30] as follows:

$$
\varepsilon=\left(1-\frac{\rho_{b}}{\rho_{t}}\right) \times 100
$$

True density $\left(\rho_{t}\right)$ was determined using a standard liquid pycnometer by determining the volume of the sample at various moisture contents. Volume $\left(V, \mathrm{~cm}^{3}\right)$ was calculated from the following relationship [31]:

$$
V=\frac{\left(M_{p s}-M_{p}\right)-\left(M_{p t s}-M_{t}\right)}{\rho_{\text {tol }}}
$$

where $M_{t}$ is mass of the pycnometer filled with toluene, $M_{p s}$ is the mass of pycnometer and sample, $M_{p}$ is mass of the pycnometer, $M_{p t s}$ is mass of the pycnometer filled with toluene and sample, and $\rho_{\text {tol }}$ is the density of toluene. Knowing $V$, the true density $(\mathrm{g} / \mathrm{cc})$ then can be calculated from the following expression:

$$
\rho_{t}=\frac{\left(M_{p s}-M_{p}\right)}{V} .
$$

Bulk density $\left(\rho_{b}\right)$ is estimated by weighing the samples $(70 \% \mathrm{mc})$ after pouring in a vessel of known volume $(10 \mathrm{~mL})$ [30].

2.4. Analysis of Physical Parameters: Volumetric Specific Surface $\left(\mathrm{cm}^{-1}\right)$. Volumetric specific surface is defined as external surface area per unit volume of the samples [32]. Volumetric specific surface of samples was determined from particle size analysis [33]. Samples were sieved using USA standard testing sieves stacked in order of decreasing aperture size above the collection pan placed in Ro-Tap sieve sifter (Laval Lab Inc., Canada). Weight of oversize generated during sieving was used to compute geometric mean diameter $\left(d_{\mathrm{gw}}\right)$ and geometric standard deviation $\left(S_{\mathrm{gw}}\right)$ according to the following equations:

$$
\begin{gathered}
d_{\mathrm{gw}}=\log ^{-1}\left(\frac{\sum\left(W_{i} \log d_{i}\right)}{\sum W_{i}}\right) \\
S_{\mathrm{gw}}=\log ^{-1} \sqrt{\left(\frac{\sum\left[W_{i}\left(\log d_{i}-\log d_{\mathrm{gw}}\right)^{2}\right]}{\sum W_{i}}\right)},
\end{gathered}
$$

where $d_{i}$ is the diameter of the $i$ th sieve in the stack and $W_{i}$ is the weight fraction on the ith sieve. Using $d_{\mathrm{gw}}$ and $S_{\mathrm{gw}}$, surface area per gram was calculated as follows [33]:

$$
S\left(\mathrm{~cm}^{2} / \mathrm{g}\right)=\frac{\beta_{\mathrm{s}}}{\rho \beta_{v}} \exp \left(0.5 \ln ^{2} S_{\mathrm{gw}}-\ln d_{\mathrm{gw}}\right) .
$$

Volumetric specific surface $\left(S A, \mathrm{~cm}^{-1}\right)$ can then be obtained from $(5 \mathrm{a})$ by multiplying it with specific weight $(\rho)\left(\mathrm{g} / \mathrm{cm}^{3}\right)$, that is,

$$
S A\left(\mathrm{~cm}^{-1}\right)=\frac{\beta_{\mathrm{s}}}{\beta_{\mathrm{v}}} \exp \left(0.5 \ln ^{2} S_{\mathrm{gw}}-\ln d_{\mathrm{gw}}\right),
$$

where $\beta_{s}$ is the shape coefficient for calculating surface area of particles (fixed at 6) and $\beta_{v}$ is the shape coefficient for calculating volume of particles (fixed at 1) [33].

2.5. Analysis of Physical Parameters: Wide-Angle X-Ray Diffraction. Wide-angle X-ray diffraction (XRG 3100 X-ray generator, Phillips Electronics Instrument Inc., TX, USA) was used to estimate the crystallinity of native and pretreated soybean hulls. The $\mathrm{X}$-rays from a $\mathrm{Cu}$ tube operating at $35 \mathrm{KV}$ and $20 \mathrm{~mA}$ were collected by an energy dispersive detector that is able to resolve $\mathrm{CuK}_{\alpha}$ line. Counts were collected at a step size of $0.02^{\circ}$ at a series of angles between $5^{\circ}$ and $40^{\circ}$. Speed of count collection was $0.6^{\circ} / \mathrm{min}$.

2.6. Analysis of Physical Parameters: Crystallinity Calculations Using Deconvolution Method. The raw diffractograms were subjected to a fitting procedure using a nonlinear least squares numerical procedure. The deconvolution method separates amorphous and crystalline contributions to the diffraction spectrum under curve-fitting process by selecting a shape function [34]. In this method it is very important to understand the major sources that contribute to the shape function of the observed X-ray profile $h(2 \theta)$, which is a convolution $(\Theta)$ of the intrinsic specimen profile $f(2 \theta)$ with the spectral distribution $(W)$ and the instrumental function $(G)$ superimposed over the background $b$ [35], as given below:

$$
h(2 \theta)=[(W \Theta G) \Theta f](2 \theta)+b .
$$

The Voigt function, which is a convolution of Gaussian and Lorentzian peak functions, would include both Gaussian intrinsic broadening of the specimen along with the Lorentzian instrumental profile that considers the background from amorphous scattering. The Voigt function, therefore, appropriately takes into account the peak broadening due to diffusive scattering $[35,36]$.

Using the Voigt function intensity of the reflection is represented by following equation [35]:

$$
=\frac{a_{o} \int_{-\infty}^{\infty}\left(\exp \left(-(2 \theta)^{2}\right) /\left(a_{l}^{2}+\left(\left(x-a_{\mathrm{c}}\right) / a_{\mathrm{g}}-2 \theta\right)^{2}\right)\right) d(2 \theta)}{\int_{-\infty}^{\infty}\left(\exp \left(-\left(-(2 \theta)^{2}\right)\right) /\left(a_{l}^{2}+(2 \theta)\right)\right) d(2 \theta)},
$$

where $a_{o}$ is the amplitude of the peak, $a_{\mathrm{c}}$ is the center of the peak, $a_{l}$ is the width of the Lorentzian component, and $a_{g}$ is the width of the Gaussian component of the peak. The major reflective planes in cellulosic material from plant sources correspond to the following Miller indices (hkl): 101, $10 \overline{1}, 002,021$, and 040, with 002 as the prominent reflection representing crystalline cellulose (sometimes resolved into 021 plane as well) [37]. X-ray peaks were fitted using Voigt function as profile shape function using Peakfit (SeaSolve Software Inc., MA, USA) program. The program was rerun locking these planes; consequently, five Voigt functions were fitted. The fitted peaks were used to evaluate degree of 
crystallinity $\left(X_{\mathrm{cr}}\right)$ of the sample per (8) described by Wada et al. [36],

$$
X_{\mathrm{cr}}(\%)=\frac{I_{002}+I_{021}}{I_{101}+I_{10 \bar{T}}+I_{002}+I_{021}+I_{040}} \times 100,
$$

where $I$ followed by a subscript represents the integrated intensity of the particular Bragg plane. Crystallinity, therefore, represents the fraction of $\alpha$-cellulose represented by planes 002 and 021 present in a particular sample.

2.7. Analytical Methods: Compositional Analysis. The lignocellulosic composition of soybean hulls was determined with an ANKOM 200 Fiber Analyzer (ANKOM Technology, USA). Neutral detergent fiber (NDF), acid detergent fiber (ADF), and acid detergent lignin (ADL) were analyzed per procedure specified by the manufacturer (http://www.ankom.com). Protein content $(N \times 6.25)$ was determined by the Kjeldahl method after digestion and distillation with an autoanalyser (Leco FP-2000, Leco Corporation, MI, USA). All moisture measurements were carried out using Denver Infrared Moisture Analyzer (Model IR35; Fisher Scientific, USA). Ash content of soybean hulls was measured using muffle furnace from Fisher Scientific.

2.8. Enzyme Assay. Crude cellulases were extracted from various production steps described in Section 2.4 by adding $30 \mathrm{~mL}$ of citrate buffer (50 mM, pH 5) to each flask and shaking the contents at $150 \mathrm{rpm}$ for 30 minutes. Contents were filtered using coarse filter paper (Fisher Scientific, P-8 coarse grade), and the filtrate obtained was centrifuged at 10,000 $\times \mathrm{g}$ for 15 minutes at $4^{\circ} \mathrm{C}$ (Sorvall RC-6, Thermo Scientific, USA). The supernatant was analyzed for filter paper activity (FPU/g-ds), endocellulase (IU/g-ds), $\beta$-glucosidase (IU/g$\mathrm{ds}$ ), and xylanase (IU/g-ds) activities. Enzymatic assays were carried out using standard protocols described in Brijwani et al. [29]. Enzyme activities were reported as units per gram of dry substrate (g-ds).

2.9. Statistical Analysis. Statistical analysis was carried out using the GLM procedure in SAS software version 9.1 (SAS Institute, Cary, NC, USA). Multiple comparisons were conducted using Tukey Kramer HSD at $P<.05$.

\section{Results and Discussion}

3.1. Effect of Pretreatments on Compositional Changes in Soybean Hulls. Effects of various pretreatments on compositional changes in soybean hulls are shown in Table 1. Data is represented only to outline holocellulose (cellulose +hemicellulose), lignin, protein, and ash content of soybean hulls, and not necessarily embody composition fully. Soybean hulls are known to contain appreciable amount of pectin $(\sim 15 \%)$ and lipids $(<4 \%)$ as well $[38,39]$. Both acid and alkali pretreatments enriched the cellulosic fraction and extracted a small part of the hemicellulosic fraction. Steam-pretreated soybean hulls, on the other hand, had a composition similar to that of native soybean hulls. An interesting finding was that holocellulosic content was fairly constant (no significant difference, $P<.05$ ) across the spectrum of treatments used in this study (Table 1). Total cellulosic content may be useful to consider because both cellulose and hemicellulose are implicated in induction of cellulolytic enzyme complex [40]. Henceforth, subjecting soybean hulls to mild pretreatments preserved the holocellulosic composition of native soybean hulls.

\subsection{Effect of Pretreatments on Changes in Physical Attributes} of Soybean Hulls: Bed Porosity and Volumetric Specific Surface of Pretreated Soybean Hulls. There was a substantial increase in the bed porosity (Table 2), estimated at $70 \% \mathrm{mc}$, for pretreated soybean hulls compared with native soybean hulls. The increase in bed porosity is likely due to modification of the internal structure of soybean hulls that led to redistribution and partial solubilization of hemicellulose and swelling of the substrate [42]. Volumetric specific surface $\left(\mathrm{cm}^{-1}\right)$, on the other hand, was similar for pretreated and native soybean hulls. Notably, volumetric specific surface measurements were the outcome of particle size analysis that accounted only for external surface area; however, fibers have lumen characterized by hollow space. It is the interfibrillar space sometimes referred to as "internal porosity" that has capability of accommodating large enzyme molecules and leads to thorough digestibility. Chemical pretreatment tends to enlarge intermicrofibrillar spaces by dissolution of cell wall capillaries [18]. Unfortunately, finding a simple technique to determine lumen internal surfaces is difficult, and volumetric specific surface incorporating external particle diameter is unable to capture the internal specific area, which characterizes microfibrillar spaces [32]. This was evident in the current study when the volumetric specific surface of pretreated and untreated soybean hulls were not significantly different $(P<.05)$. Apparently, it seems essential to identify or modify current techniques that can easily implement rapid and routine analysis of internal surface area, and therefore warrants future investigations.

3.3. X-Ray Crystallinity of Native and Pretreated Soybean Hulls. Wide-angle X-ray diffraction has been used extensively to measure the crystallinity of cellulosic substrates. Crystallinity in the polymeric sample may be measured in several ways from an X-ray diffractogram; the most common is the peak intensity method [43]. The method requires amorphous material to diffract with the same intensity at $18^{\circ}$ ( $\sim 10 \overline{1}$ plane) and $22^{\circ}$ (002 plane), and does not account for peak shifting or overlap. Moreover, the crystallinity values predicted by this method are usually overestimated [25]. Further, this method assumes highest peak (002) as the only determinant of the cellulose crystallinity [34], which is certainly not the case as five planes have been identified responsible for the characteristic reflection. Finally, lignocellulosic substrates contain appreciable amounts of hemicellulose and lignin that lead to diffusive X-ray scattering (reflection), a hallmark of paracrystalline substances [44, 45]. Given these drawbacks of the peak intensity method, a sophisticated technique using deconvolution was successfully applied in our studies to X-ray spectra of both native and pretreated 
TABLE 1: Composition of various substrates (dry basis).

\begin{tabular}{lcccccc}
\hline Sample & Cellulose (ADF-ADL) & Hemicellulose (NDF-ADF) & Holocellulose & Lignin (ADL) & Protein & Ash \\
\hline Native soybean hulls & $45.90 \pm 0.60$ & $19.59 \pm 0.57$ & $65.48 \pm 1.14^{\mathrm{A}}$ & $0.75 \pm 0.09$ & $11.96 \pm 0.06$ & $5.21 \pm 0.01$ \\
Steam-treated soybean hulls & $49.99 \pm 2.67$ & $19.32 \pm 0.83$ & $69.31 \pm 3.38^{\mathrm{A}}$ & $1.19 \pm 0.15$ & $10.43 \pm 0.07$ & $2.67 \pm 0.05$ \\
$\mathrm{HCl}-$ treated soybean hulls & $57.19 \pm 0.40$ & $15.33 \pm 0.96$ & $72.52 \pm 1.08^{\mathrm{A}}$ & $1.33 \pm 0.07$ & $9.60 \pm 0.03$ & $2.55 \pm 0.05$ \\
$\mathrm{H}_{2} \mathrm{SO}_{4}$-treated soybean hulls & $54.74 \pm 0.47$ & $17.39 \pm 0.77$ & $72.14 \pm 1.23^{\mathrm{A}}$ & $1.47 \pm 0.19$ & $10.11 \pm 0.11$ & $2.78 \pm 0.08$ \\
$\mathrm{NaOH}$-treated soybean hulls & $60.45 \pm 1.61$ & $15.66 \pm 1.58$ & $76.11 \pm 3.15^{\mathrm{A}}$ & $1.23 \pm 0.03$ & $3.45 \pm 0.06$ & $3.26 \pm 0.06$ \\
\hline
\end{tabular}

${ }^{*}$ Represents sum of cellulose and hemicellulose; data are expressed as mean \pm SE; $n=4$; means with same letters do not differ significantly. Pairwise comparisons between total cellulosics were tested using Tukey Kramer HSD at $P<.05$.

TABLE 2: Physical attributes of various substrates.

\begin{tabular}{|c|c|c|c|c|c|}
\hline Sample & $\begin{array}{c}\text { Degree of } \\
\text { crystallinity }(\%)\end{array}$ & $\begin{array}{c}\text { Adj. } R^{2} \text { for X-ray } \\
\text { fitting }\end{array}$ & $\begin{array}{l}\text { RMSE for X-ray } \\
\text { fitting }\end{array}$ & Bed porosity (\%) & $\begin{array}{c}\text { Volumetric specific } \\
\text { surface }\left(\mathrm{cm}^{-1}\right)\end{array}$ \\
\hline $\begin{array}{l}\text { Native } \\
\text { soybean hulls }\end{array}$ & $42.56 \pm 3.34$ & 0.91 & 15.06 & $40.41 \pm 1.91$ & $122.28 \pm 1.91$ \\
\hline $\begin{array}{l}\text { Steam- } \\
\text { treated } \\
\text { soybean hulls }\end{array}$ & $57.16 \pm 2.39$ & 0.94 & 12.48 & $57.45 \pm 0.50$ & $120.41 \pm 2.34$ \\
\hline $\begin{array}{l}\text { HCl-treated } \\
\text { soybean hulls }\end{array}$ & $56.29 \pm 0.12$ & 0.94 & 13.40 & $53.65 \pm 0.12$ & $120.28 \pm 2.47$ \\
\hline $\begin{array}{l}\mathrm{H}_{2} \mathrm{SO}_{4-}^{-} \\
\text {treated } \\
\text { soybean hulls }\end{array}$ & $56.53 \pm 0.12$ & 0.95 & 13.35 & $50.02 \pm 0.68$ & $120.77 \pm 2.16$ \\
\hline $\begin{array}{l}\mathrm{NaOH}- \\
\text { treated } \\
\text { soybean hulls }\end{array}$ & $59.72 \pm 0.43$ & 0.96 & 11.70 & $56.77 \pm 0.57$ & $128.09 \pm 1.84$ \\
\hline
\end{tabular}

Data are expressed as mean $\pm \mathrm{SE} ; n=4$. It should be noted that RMSE values are scaled on $y$-axis that represents X-ray intensities of various peaks corresponding to Bragg planes. Peak values are usually in the range of 100-500 counts.

soybean hulls for crystallinity measurements. This method is relatively new in the arena of lignocellulosic biofuels research, although it is routinely used in polymer science research [41].

The fitted X-ray diffractograms using Voigt function are shown in Figures 1(a)-1(e) for both native and pretreated soybean hulls. Fit was assessed using $R^{2}$. Almost all diffractograms using this scheme had $R^{2}>0.95$. Also, featured in the Table 2 are adjusted $R^{2}$ (Adj. $R^{2}$ ) and root mean square error (RMSE) of the fit. The higher value of adjusted $R^{2}$ and lower RMSE further confirmed the goodness of fit. Notice the five peaks corresponding to identified lattice planes and gradual evolution of peaks in pretreated soybean hulls compared to native soybean hulls indicating increase in degree of crystallinity due to pretreatments. Degree of crystallinity was calculated from (8), and the values are listed in Table 2. The steam, acid, and alkali pretreatments all resulted in a significant increase in degree of crystallinity compared to native soybean hulls. The pretreated soybean hulls had crystallinity from 57 to $59 \%$ (Table 2). The enhancement in crystallinity is due to enrichment in the $\alpha$ cellulose fraction in the pretreated samples due to reduction in the interlocking amorphous cellulosic chains and plausible correction in lattice defects of cellulose during pretreatments $[46,47]$. The $\alpha$-cellulose fraction is the crystalline cellulose of plant polymers and is responsible for the characteristic $\mathrm{X}$-ray diffraction. Additionally, due to the mild nature of pretreatments, enrichment in $\alpha$-cellulose fraction was possible by selective reduction of the amorphous phase. The outcome could have been different if harsh chemical pretreatments (using high temperature and pressure) were employed.

3.4. Effect of Pretreatment Methods on Production of Cellulolytic Enzyme System. Production of a cellulolytic enzyme system was assessed through measurement of four leading activities: filter paper units (FPU/g-ds (dry substrate)), $\beta$ glucosidase (IU/g-ds), endocellulase (IU/g-ds), and xylanase (IU/g-ds). Inspection of Figure 2 reveals that enzyme production in both mono and mixed cultures of $T$. reesei and A. oryzae was significantly reduced in alkali-pretreated soybean hulls compared to native, steam-, and acid-pretreated substrates. Gossett et al. [48] stated that an important aspect of alkali pretreatment is that biomass itself consumes some of the alkali. As a result, changes brought about by alkali pretreatment can cause solubilization, distribution, and condensation of lignin and hemicellulose and modification of cellulosic structure. These effects can counter the positive effects rendered by alkali pretreatment. Aiello et al. [49] showed that alkali-pretreated sugarcane bagasse in liquid fermentation of $T$. reesei (QM 9414) significantly decreased cellulase yield over untreated bagasse. Cellulolytic enzyme production in $\mathrm{HCl}$ - and $\mathrm{H}_{2} \mathrm{SO}_{4}$-pretreated soybean hulls was significantly $(P<.05)$ lower as well for both cultures compared to production in both native and steam-pretreated substrates. Acid pretreatment of lignocellulosics is known 
TABLE 3: Effect of interaction between crystallinity and bed porosity of substrates on cellulolytic enzyme production in both mono and mixed SSF of T. reesei and A. oryzae.

\begin{tabular}{|c|c|c|c|c|c|c|}
\hline \multirow[t]{2}{*}{ Interaction } & \multirow[t]{2}{*}{ Culture } & \multicolumn{4}{|c|}{ Cellulolytic enzyme system } & \multirow{2}{*}{$\begin{array}{l}\text { Treatments } \\
\text { considered }\end{array}$} \\
\hline & & $\begin{array}{c}\text { Filter paper } \\
\text { units } \\
(\text { FPU/g-ds) }\end{array}$ & $\begin{array}{l}\beta \text {-glucosidase } \\
\text { (IU/g-ds) }\end{array}$ & $\begin{array}{l}\text { Endoglucanase } \\
\text { (IU/g-ds) }\end{array}$ & $\begin{array}{l}\text { Xylanase } \\
\text { (IU/g-ds) }\end{array}$ & \\
\hline $\begin{array}{l}\text { Crystallinity } \\
\times \text { porosity }\end{array}$ & $\begin{array}{c}\text { Trichoderma } \\
\text { reesei }\end{array}$ & $<0.0001^{*}$ & $0.0388^{*}$ & $<0.0001^{*}$ & 0.0472 & Native, steam \\
\hline $\begin{array}{l}\text { Crystallinity } \\
\times \text { porosity }\end{array}$ & $\begin{array}{l}\text { Aspergillus } \\
\text { oryzae }\end{array}$ & 0.4629 & 0.9218 & $0.0005^{*}$ & 0.9912 & Native, steam \\
\hline $\begin{array}{l}\text { Crystallinity } \\
\times \text { porosity }\end{array}$ & Mixed & $0.0044^{*}$ & 0.0449 & $0.0257^{* *}$ & 0.9061 & Native, steam \\
\hline
\end{tabular}

${ }^{*}$ Indicates Tukey probability for a particular interaction is significant at $95 \%$ confidence. ${ }^{* *}$ Indicates significance at $P<.05$ but not significance at $P<.01$. Model (9) ran in SAS 9.1.

Abbreviations: native, untreated soybean hulls; steam, steam-pretreated soybean hulls.

to generate inhibitory compounds as result of sugar and lignin degradation during the treatments $[50,51]$. Though the acid pretreatment may result in increased digestibility of lignocellulosic substrate, the inhibitory compounds have deleterious effects on enzyme and microbial activity.

Steam pretreatment resulted in significant $(P<.05)$ and substantial enhancement in production of all cellulolytic activities in $T$. reesei culture compared to production in untreated soybean hulls. The production of xylanase, though, was not significantly $(P<.05)$ different. Steampretreated soybean hulls had about $4 \mathrm{FPU} / \mathrm{g}$-ds compared with $0.75 \mathrm{FPU} / \mathrm{g}$-ds in native and endocellulase of $45 \mathrm{IU} / \mathrm{g}$-ds compared with $7.29 \mathrm{IU} / \mathrm{g}$-ds in native. $\beta$-glucosidase activity also improved significantly $(P<.05)$ in steam-pretreated compared with native soybean hulls. The preponderance of these results is apparent from the fact that both native and steam pretreated soybean hulls had compositional similarity (Table 1) but significantly different enzyme production (Figure 2). This is a key indication that in SSF, in which fungal mycelium is in direct contact with the substrate particles, the physicochemical nature of the substrate is important in addition to its composition.

In $A$. oryzae no significant differences $(P<.05)$ occurred in enzyme production between steam-pretreated and native soybean hulls except in endoglucanase levels. In steampretreated soybean hulls, A. oryzae produced a significantly higher amount of endoglucanase (47 IU/g-ds) compared to that in native substrate (31 IU/g-ds). Mixed culture had similar results as in A. oryzae, where production in steampretreated soybean hulls was not significantly different $(P<$ .05 ) compared to native soybean hulls (Figure 2).

The foregoing indicated steam pretreatment had disparities in enzyme production, which were both enzyme and culture specific. To relate the trends in enzyme production with physicochemical characteristics of the substrate in the two fungal cultures, $T$. reesei and A. oryzae, additional statistical analysis was performed.

3.5. Effect of Interaction between Crystallinity and Porosity in Cellulolytic Enzyme System Production in Pretreated Substrates. The interaction of crystallinity and porosity was modeled using the general linear model of SAS with the following expression:

$$
y_{i j k}=\mu+a b_{i j}+\epsilon_{i j k}
$$

where is one of the enzyme activities as the dependent variable, $\mu$ is the grand mean $(n=4), a b_{i j}$ is the interaction effect of crystallinity and porosity, and $\epsilon_{i j k}$ is random error with mean 0 and experimental error variance as its variance. Both composition (holocellulose) and volumetric specific surface were excluded as they were nearly constant across pretreatments (Tables 1 and 2). In addition, only native and steam pretreated substrates were considered in our analysis because enzyme production in acid- and alkali-pretreated substrates was lower due to their inhibitory effects on microbial propagation. Crystallinity and porosity were considered together because both of them were simultaneously altered when substrates were subjected to pretreatments. It was not possible to keep one constant and make other variable during pretreatments. Broadly speaking, the model represented by (9) is more reflective of one-way variance analysis than factorial variance analysis.

Examination of data (Table 3) shows that for T. reesei, with an increase in crystallinity and porosity due to steam pretreatment, all cellulolytic enzyme activities increased significantly except xylanase. In A. oryzae fermentation, significant improvement was noticed only in endoglucanase production whereas, in mixed culture fermentation, significant decrease occurred in filter paper units at $P<.01$ and endoglucanase at $P<.05$ as a result of increased crystallinity and porosity.

Bed porosity ensures oxygen availability between the moist substrate particles. It is plausibly implicated in the propagation of fungal cultures and, therefore, affects enzyme production. Rahardjo et al. $[8,9]$ explained this phenomenon by using various model substrates that differed in the amount of open spaces for production of $\alpha$-amylase in solid-state cultures of $A$. oryzae and explicitly showed that model substrates with more porous structure had better enzyme production compared to less porous substrates. Therefore, decrease in filter paper and endoglucanases activities in mixed culture compared to T. reesei could be attributed 


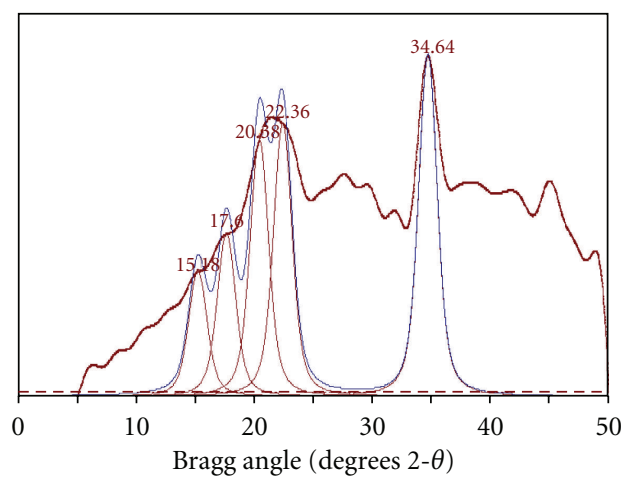

(a)

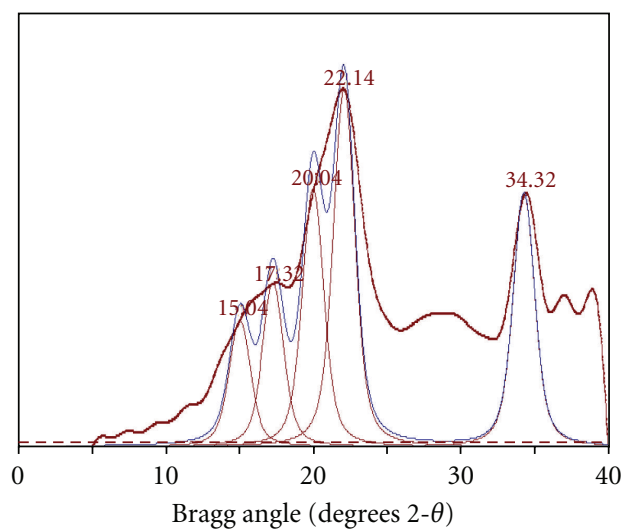

(c)

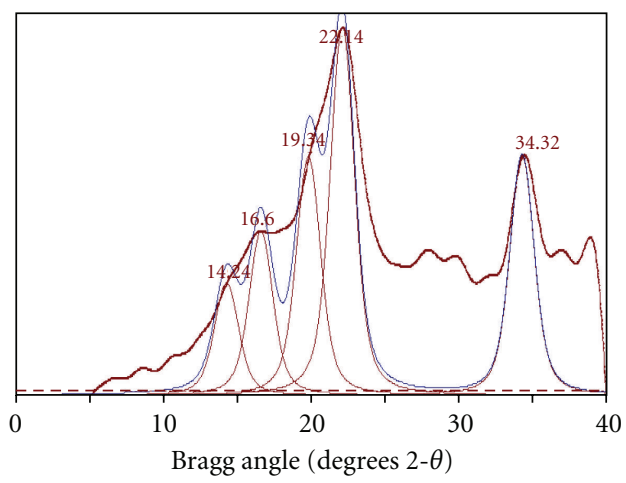

(b)

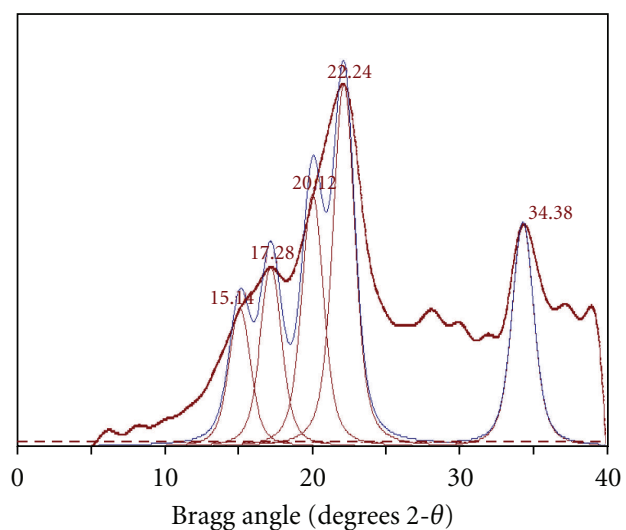

(d)

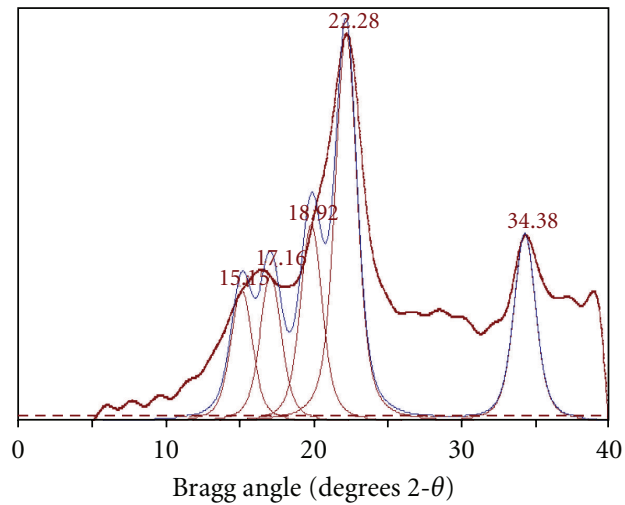

(e)

FIGURE 1: X-ray diffractograms. Gaussian smoothing followed by Voigt function was used to fit the diffractogram output of the instrument. (a) Native soybean hulls. (b) Steam-pretreated soybean hulls. (c) $\mathrm{HCl}$-pretreated soybean hulls. (d) $\mathrm{H}_{2} \mathrm{SO}_{4}$-pretreated soybean hulls. (e) $\mathrm{NaOH}$-pretreated soybean hulls. Planes corresponding to $2 \theta$ are 101 plane $\left(\sim 15^{\circ}\right), 10 \overline{1}\left(\sim 17^{\circ}\right), 021$ plane $\left(\sim 20^{\circ}\right), 002$ plane $\left(\sim 22^{\circ}\right)$, and 040 plane $\left(\sim 34^{\circ}\right)$. (Adapted from [41]).

to another factor that is, increase in crystallinity. It is apparent from the literature that $T$. reesei cellulases are particularly active towards crystalline cellulose [20, 52, 53]; however, enzymes from Aspergillus spp. lack ability to degrade crystalline cellulose $[54,55]$. In mixed culture fermentation wherein A. oryzae was dominant, filter paper and endocellulase activities were reduced due to the inability of $A$. oryzae to digest crystalline substrate. This is further confirmed by observing the data of $A$. oryzae fermentation, where no improvement in cellulolytic activities in steam-pretreated soybean hulls over native substrate was observed except in endoglucanase activity.

Evidently, results highlighted that effect of crystallinity was specific for type of culture as it brought enhancement in cellulolytic activities of $T$. reesei, and this enhancement was not particularly observed in A. oryzae. The analysis also showed that within the spectrum of cellulolytic activities studied not all activities got altered on exposure to crystalline substrate. The results are interesting in view of the fact that pretreatments due to their ability to induce changes in 


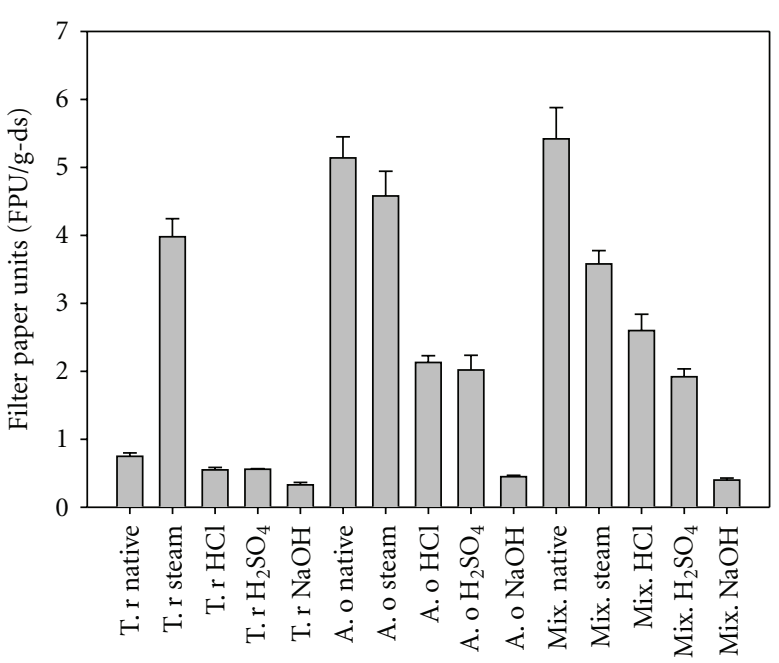

(a)

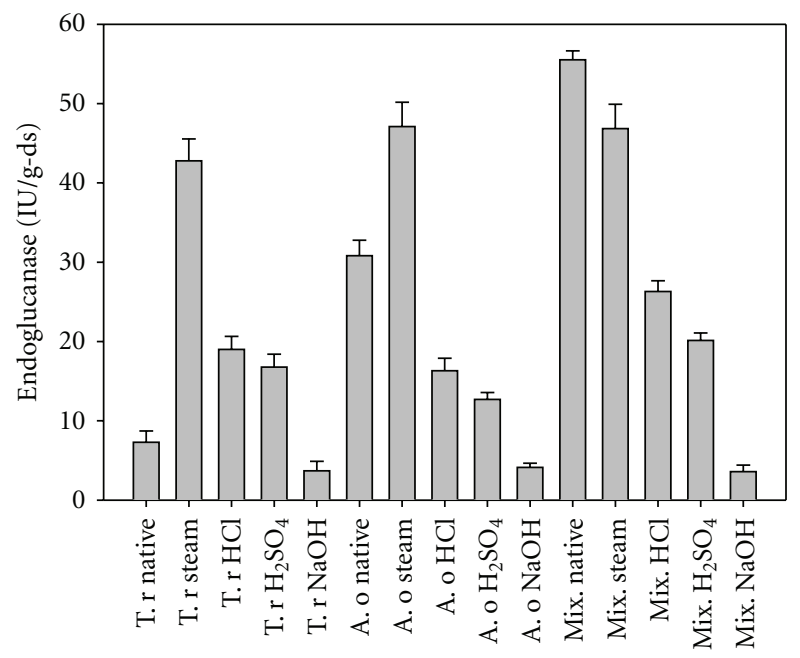

(c)

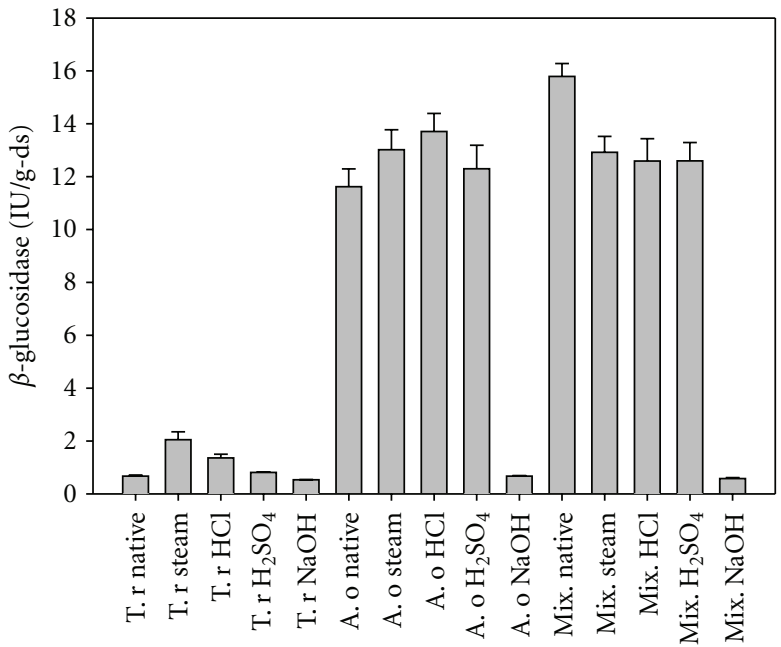

(b)

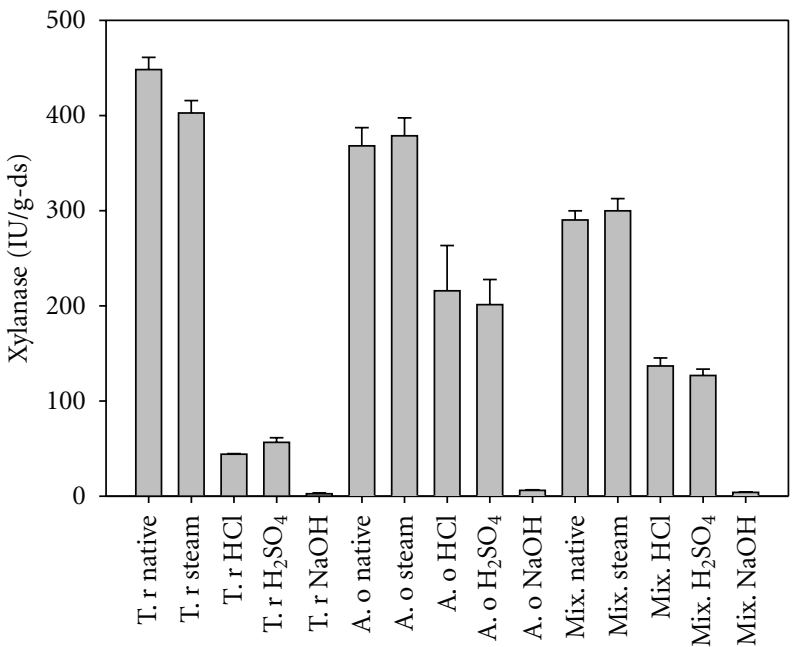

(d)

FIGURE 2: Effect of different pretreatments on cellulolytic enzyme production in 5 days grown mono and mixed cultures of Trichoderma reesei and Aspergillus oryzae. (a) Filter paper activity. (b) $\beta$-glucosidase activity. (c) Endocellulase activity. (d) Xylanase activity. Abbreviations: T. r, T. reesei; A. o, Aspergillus oryzae; mix, 1:1 mixture of T. reesei and A. oryzae cultures; native, untreated soybean hulls; steam, steam-pretreated soybean hulls; $\mathrm{HCl}$, hydrochloricacid-pretreated soybean hulls; $\mathrm{H}_{2} \mathrm{SO}_{4}$, sulfuric-acid-pretreated soybean hulls; $\mathrm{NaOH}$, sodiumhydroxidepretreated soybean hulls. Refer to text for more details on conditions of pretreatments. Data are expressed as mean \pm SE, $n=4$.

physicochemical attributes resulted in altered enzyme production in fungal SSF of soybean hulls.

\section{Conclusions}

For the first time, current work demonstrated that mild pretreatment methods could significantly alter the physicochemical attributes of the substrate (soybean hulls) without significant changes in holocellulosic composition. The altered physicochemical attributes due to pretreatment had significant effects on the production of cellulolytic enzyme activities, and these effects were both culture and enzyme specific. A sophisticated deconvolution method was used to determine X-ray crystallinity from raw diffractograms of both treated and untreated substrates. This method takes into account diffusive scattering due to paracrystalline nature of celluloses found in plant material, and therefore provides consistent and reliable measurements. Steam pretreatment significantly increased both porosity and crystallinity of soybean hulls, and production of all the three cellulase activities in $T$. reesei culture (i.e., filter paper, $\beta$-glucosidase, and endocellulase) compared to untreated substrate. Xylanase production, however, remained unaltered. While using $A$. oryzae culture, significant improvement was observed only in endocellulase whereas in the mixed culture fermentation, filter paper, and endocellulase activities decreased in steampretreated soybean hulls.

Further study of porosity and crystallinity and their effects on enzyme production is necessary if we are to understand fully the effects of physiochemical attributes. Our studies highlighted the effects of pretreatment methods, 
changes in the physiochemical characteristics of substrates, and choice of fungal culture in SSF on enzyme production. Experimental methods to enhance enzyme production are imperative for the success of the biofuels industry, which uses enzymatic and microbial fermentation platform.

\section{Acknowledgments}

The authors are grateful to the Center for Sustainable Energy and the Department of Grain Science and Industry, Kansas State University, for funding this project. Authors gratefully acknowledge Dr. Paul A. Seib, Department of Grain Science, Kansas State University for helpful discussions. This paper is contribution no. 10-301-J from the Kansas Agricultural Experiment Station, Manhattan. Authors hereby disclose all conflicts of interest and other potentially conflicting interests, including specific financial interests and relationships and affiliations relevant to use of chemicals, software products, and equipment from the suppliers featured in this study, but not limited to employment or affiliation, grants or funding, consultancies, honoraria, speakers' bureaus, stock ownership or stock options, expert testimony, and royalties received, pending, or in preparation. This applies to the past 5 years and the foreseeable future.

\section{References}

[1] Y. H. P. Zhang, M. E. Himmel, and J. R. Mielenz, "Outlook for cellulase improvement: screening and selection strategies," Biotechnology Advances, vol. 24, no. 5, pp. 452-481, 2006.

[2] Y. H. P. Zhang and L. R. Lynd, “Toward an aggregated understanding of enzymatic hydrolysis of cellulose: noncomplexed cellulase systems," Biotechnology and Bioengineering, vol. 88, no. 7, pp. 797-824, 2004.

[3] R. R. Singhania, R. K. Sukumaran, A. K. Patel, C. Larroche, and A. Pandey, "Advancement and comparative profiles in the production technologies using solid-state and submerged fermentation for microbial cellulases," Enzyme and Microbial Technology, vol. 46, no. 7, pp. 541-549, 2010.

[4] S. R. Couto and M. A. Sanromán, "Application of solidstate fermentation to food industry-a review," Journal of Food Engineering, vol. 76, no. 3, pp. 291-302, 2006.

[5] C. Botella, A. B. Diaz, R. Wang, A. Koutinas, and C. Webb, "Particulate bioprocessing: a novel process strategy for biorefineries," Process Biochemistry, vol. 44, no. 5, pp. 546-555, 2009.

[6] T. L. Richard, A. H. M. Veeken, V. de Wilde, and H. V. M Hamelers, "Air-filled porosity and permeability relationships during solid-state fermentation," Biotechnology Progress, vol. 20, no. 5, pp. 1372-1381, 2004.

[7] Y. Q. Cui, R. G. J. M. Van der Lans, and K. CH. A. M. Luyben, "Effects of dissolved oxygen tension and mechanical forces on fungal morphology in submerged fermentation," Biotechnology and Bioengineering, vol. 57, no. 4, pp. 409-419, 1998.

[8] Y. S. P. Rahardjo, F. Jolink, S. Haemers, J. Tramper, and A. Rinzema, "Significance of bed porosity, bran and specific surface area in solid-state cultivation of Aspergillus oryzae," Biomolecular Engineering, vol. 22, no. 4, pp. 133-139, 2005.

[9] Y. S. P. Rahardjo, F. J. Weber, S. Haemers, J. Tramper, and A. Rinzema, "Aerial mycelia of Aspergillus oryzae accelerate $\alpha$-amylase production in a model solid-state fermentation system," Enzyme and Microbial Technology, vol. 36, no. 7, pp. 900-902, 2005.

[10] J. Chutmanop, S. Chuichulcherm, Y. Chisti, and P. Srinophakun, "Protease production by Aspergillus oryzae in solidstate fermentation using agroindustrial substrates," Journal of Chemical Technology and Biotechnology, vol. 83, no. 7, pp. 1012-1018, 2008.

[11] S. Velkovska, M. R. Marten, and D. F. Ollis, "Kinetic model for batch cellulase production by Trichoderma reesei RUT C30," Journal of Biotechnology, vol. 54, no. 2, pp. 83-94, 1997.

[12] F. C. Domingues, J. A. Queiroz, J. M. S. Cabral, and L. P. Fonseca, "The influence of culture conditions on mycelial structure and cellulase production by Trichoderma reesei rut C-30," Enzyme and Microbial Technology, vol. 26, no. 5-6, pp. 394-401, 2000.

[13] L. P. Walker and D. B. Wilson, "Enzymatic-hydrolysis of cellulose: an overview," Bioresource Technology, vol. 36, no. 1, pp. 3-14, 1991.

[14] A. O. Converse, R. Matsuno, M. Tanaka, and M. Taniguchi, "A model of enzyme adsorption and hydrolysis of microcrystalline cellulose with slow deactivation of the adsorbed enzyme," Biotechnology and Bioengineering, vol. 32, no. 1, pp. 38-45, 1988.

[15] S. D. Mansfield, C. Mooney, and J. N. Saddler, "Substrate and enzyme characteristics that limit cellulose hydrolysis," Biotechnology Progress, vol. 15, no. 5, pp. 804-816, 1999.

[16] C. I. Ishizawa, M. F. Davis, D. F. Schell, and D. K. Johnson, "Porosity and its effect on the digestibility of dilute sulfuric acid pretreated corn stover," Journal of Agricultural and Food Chemistry, vol. 55, no. 7, pp. 2575-2581, 2007.

[17] M. Tanaka, M. Ikesaka, R. Matsuno, and A. O. Converse, "Effect of pore-size in substrate and diffusion of enzyme on hydrolysis of cellulosic materials with cellulases," Biotechnology and Bioengineering, vol. 32, no. 5, pp. 698-706, 1988.

[18] A. R. Esteghlalian, M. Bilodeau, S. D. Mansfield, and J. N. Saddler, "Do enzymatic hydrolyzability and Simons' stain reflect the changes in the accessibility of lignocellulosic substrates to cellulase enzymes?" Biotechnology Progress, vol. 17, no. 6, pp. 1049-1054, 2001.

[19] M. Mes-Hartree, C. M. Hogan, and J. N. Saddler, "Influence of growth substrate on production of cellulase enzymes by Trichoderma harzianum E58," Biotechnology and Bioengineering, vol. 31, no. 7, pp. 725-729, 1988.

[20] E. T. Evans, D. S. Wales, R. P. Bratt, and B. F. Sagar, "Investigation of an endoglucanase essential for the action of the cellulase system of Trichoderma reesei on crystalline cellulose," Journal of General Microbiology, vol. 138, no. 8, pp. 1639-1646, 1992.

[21] N. Hendy, C. Wilke, and H. Blanch, "Enhanced cellulase production using Solka Floc in a fed-batch fermentation," Biotechnology Letters, vol. 4, no. 12, pp. 785-788, 1982.

[22] L.T. Fan, Y. H. Lee, and D. H. Beardmore, "Mechanism of the enzymatic-hydrolysis of cellulose-effects of major structural features of cellulose on enzymatic-hydrolysis," Biotechnology and Bioengineering, vol. 22, no. 1, pp. 177-199, 1980.

[23] L.T. Fan, Y. H. Lee, and D. H. Beardmore, "The influence of major structural features of cellulose on rate of enzymatichydrolysis," Biotechnology and Bioengineering, vol. 23, no. 2, pp. 419-424, 1981.

[24] D. Ciolacu, F. Ciolacu, and V. I. Popa, "Supramolecular structure-a key parameter for cellulose biodegradation," Macromolecular Symposia, vol. 272, no. 1, pp. 136-142, 2008. 
[25] M. Hall, P. Bansal, J. H. Lee, M. J. Realff, and A. S. Bommarius, "Cellulose crystallinity-a key predictor of the enzymatic hydrolysis rate," Federation of European Biochemical Societies Journal, vol. 277, no. 6, pp. 1571-1582, 2010.

[26] P. Cen and L. Xia, "Production of cellulase in solid state ferementation," in Recent Progress in Bioconversion of Lignocellulosics, Advances in Biochemical Engineering/Biotechnology, vol. 65, p. 69, Springer, Berlin, Germany, 1999.

[27] C. Krishna, "Solid-state fermentation systems-an overview," Critical Reviews in Biotechnology, vol. 25, no. 1-2, pp. 1-30, 2005.

[28] M. Mandels and J. Weber, "Production of cellulases," Advances in Chemistry Series, vol. 95, pp. 391-414, 1969.

[29] K. Brijwani, H. S. Oberoi, and P. V. Vadlani, "Production of a cellulolytic enzyme system in mixed-culture solid-state fermentation of soybean hulls supplemented with wheat bran," Process Biochemistry, vol. 45, no. 1, pp. 120-128, 2010.

[30] R. Abalone, A. Cassinera, A. Gastón, and M. A. Lara, "Some physical properties of amaranth seeds," Biosystems Engineering, vol. 89, no. 1, pp. 109-117, 2004.

[31] E. Milani, M. Seyed, A. Razavi et al., "Moisture dependent physical properties of cucurbit seeds," International Agrophysics, vol. 21, no. 2, pp. 157-168, 2007.

[32] J. Y. Zhu, G. S. Wang, X. J. Pan, and R. Gleisner, "Specific surface to evaluate the efficiencies of milling and pretreatment of wood for enzymatic saccharification," Chemical Engineering Science, vol. 64, no. 3, pp. 474-485, 2009.

[33] S. Baker and T. Herrman, "Evaluating particle size," Kansas State University Agricultural Experiment Station and Cooperative Extension Service MF-2051, 2002.

[34] S. Park, J. O. Baker, M. E. Himmel, P. A. Parilla, and D. K. Johnson, "Cellulose crystallinity index: measurement techniques and their impact on interpreting cellulase performance," Biotechnology for Biofuels, vol. 3, article 10, 2010.

[35] C.J. Garvey, I.H. Parker, and G.P. Simon, "On the interpretation of X-Ray diffraction powder patterns in terms of the nanostructure of cellulose I fibres," Macromolecular Chemistry and Physics, vol. 206, no. 15, pp. 1568-1575, 2005.

[36] M. Wada, T. Okano, and J. Sugiyama, "Synchrotron-radiated X-Ray and neutron diffraction study of native cellulose," Cellulose, vol. 4, no. 3, pp. 221-232, 1997.

[37] R. G. Liu, H. Yu, and Y. Huang, "Structure and morphology of cellulose in wheat straw," Cellulose, vol. 12, no. 1, pp. 25-34, 2005.

[38] J. R. Mielenz, J. S. Bardsley, and C. E. Wyman, "Fermentation of soybean hulls to ethanol while preserving protein value," Bioresource Technology, vol. 100, no. 14, pp. 3532-3539, 2009.

[39] Â. C. Schirmer-Michel, S. H. Flôres, P. F. Hertz, G. S. Matos, and M. A. Z. Ayub, "Production of ethanol from soybean hull hydrolysate by osmotolerant candida guilliermondii NRRL Y2075," Bioresource Technology, vol. 99, no. 8, pp. 2898-2904, 2008.

[40] N. Aro, T. Pakula, and M. Penttilä, “Transcriptional regulation of plant cell wall degradation by filamentous fungi," FEMS Microbiology Reviews, vol. 29, no. 4, pp. 719-739, 2005.

[41] K. Brijwani and P. V. Vadlani, "Solid state fermentation of soybean hulls for cellulolytic enzymes production," in SoybeanApplications and Technology, T. B. Ng, Ed., INTECH, Vienna, Austria, 2011.

[42] P. Kumar, D. M. Barrett, M. J. Delwiche, and P. Stroeve, "Methods for pretreatment of lignocellulosic biomass for efficient hydrolysis and biofuel production," Industrial and Engineering Chemistry Research, vol. 48, no. 8, pp. 3713-3729, 2009.
[43] L. Segal, J. J. Creely, and A. E. Martin, "An empirical method for estimating the degree of crystallinity of native cellulose using X-Ray diffractometer," Textile Research Journal, vol. 29, pp. 786-794, 1959.

[44] N. Kasai and M. Kakudo, X-Ray Diffraction by Macromolecules, Springer, New York, NY, USA, 2005.

[45] C. G. Vonk, "Computerization of Rulands X-Ray method for determination of crystallinity in polymers," Journal of Applied Crystallography, vol. 6, pp. 148-152, 1973.

[46] D. Gregg and J. N. Saddler, "A techno-economic assessment of the pretreatment and fractionation steps of a biomass-toethanol process," Applied Biochemistry and Biotechnology, vol. 57-58, pp. 711-727, 1996.

[47] H. Palonen, A. B. Thomsen, M. Tenkanen, A. S. Schmidt, and L. Viikari, "Evaluation of wet oxidation pretreatment for enzymatic hydrolysis of softwood," Applied Biochemistry and Biotechnology, vol. 117, no. 1, pp. 1-17, 2004.

[48] J. M. Gossett, D. C. Stuckey, W. F. Owen, and P. L. McCarty, "Heat-treatment and anaerobic-digestion of refuse," Journal Environmental Engineering Division, ASCE, vol. 108, no. 3, pp. 437-454, 1982.

[49] C. Aiello, A. Ferrer, and A. Ledesma, "Effect of alkaline treatments at various temperatures on cellulase and biomass production using submerged sugarcane bagasse fermentation with Trichoderma reesei QM 9414," Bioresource Technology, vol. 57, no. 1, pp. 13-18, 1996.

[50] A. T. W. M. Hendriks and G. Zeeman, "Pretreatments to enhance the digestibility of lignocellulosic biomass," Bioresource Technology, vol. 100, no. 1, pp. 10-18, 2009.

[51] P. T. Pienkos and M. Zhang, "Role of pretreatment and conditioning processes on toxicity of lignocellulosic biomass hydrolysates," Cellulose, vol. 16, no. 4, pp. 743-762, 2009.

[52] C. P. Kubicek, G. Muhlbauer, and M. Klotz, "Properties of a conidial-bound cellulase enzyme-system from Trichoderma reesei," Journal of General Microbiology, vol. 134, pp. 12151222, 1988.

[53] B. Seiboth, S. Hakola, R. L. Mach, P. L. Suominen, and C. P. Kubicek, "Role of four major cellulases in triggering of cellulase gene expression by cellulose in Trichoderma reesei," Journal of Bacteriology, vol. 179, no. 17, pp. 5318-5320, 1997.

[54] N. E. Lee, M. Lima, and J. Woodward, "Hydrolysis of cellulose by a mixture of Trichoderma reesei cellobiohydrolase and Aspergillus niger endoglucanase," Biochimica Et Biophysica Acta, vol. 967, no. 3, pp. 437-440, 1988.

[55] R. P. de Vries and J. Visser, "Aspergillus enzymes involved in degradation of plant cell wall polysaccharides," Microbiology and Molecular Biology Reviews, vol. 65, no. 4, pp. 497-522, 2001. 

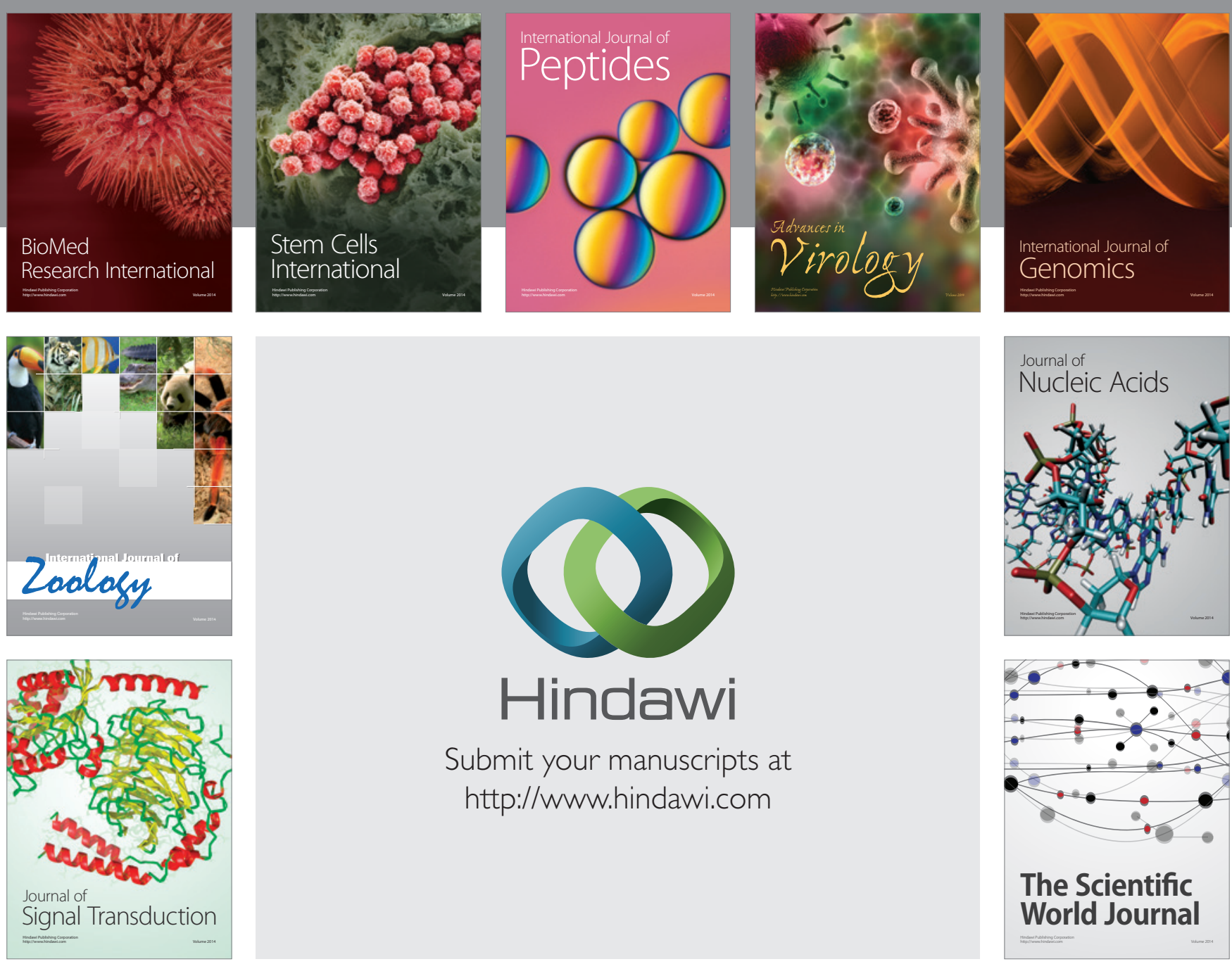

Submit your manuscripts at

http://www.hindawi.com
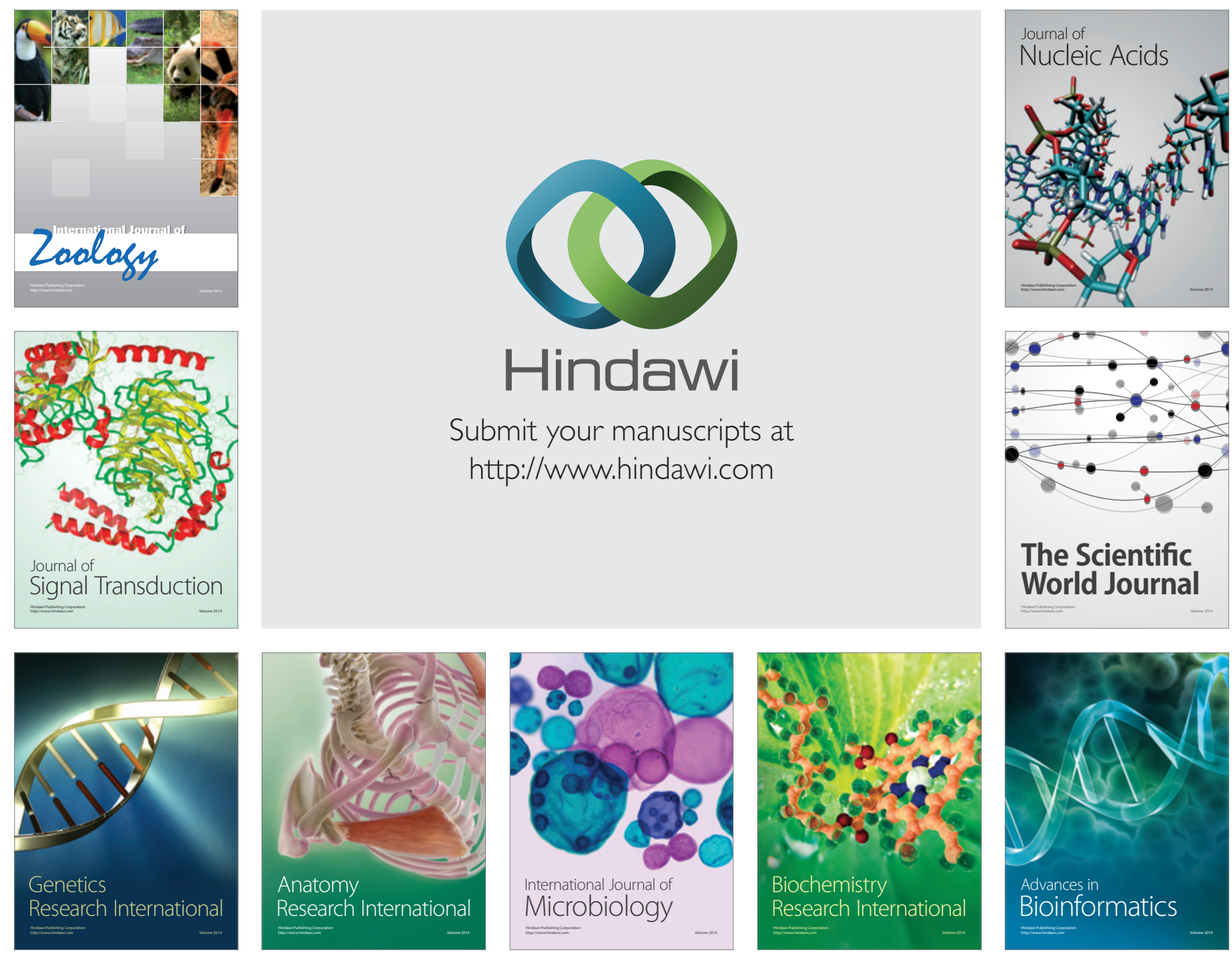

The Scientific World Journal
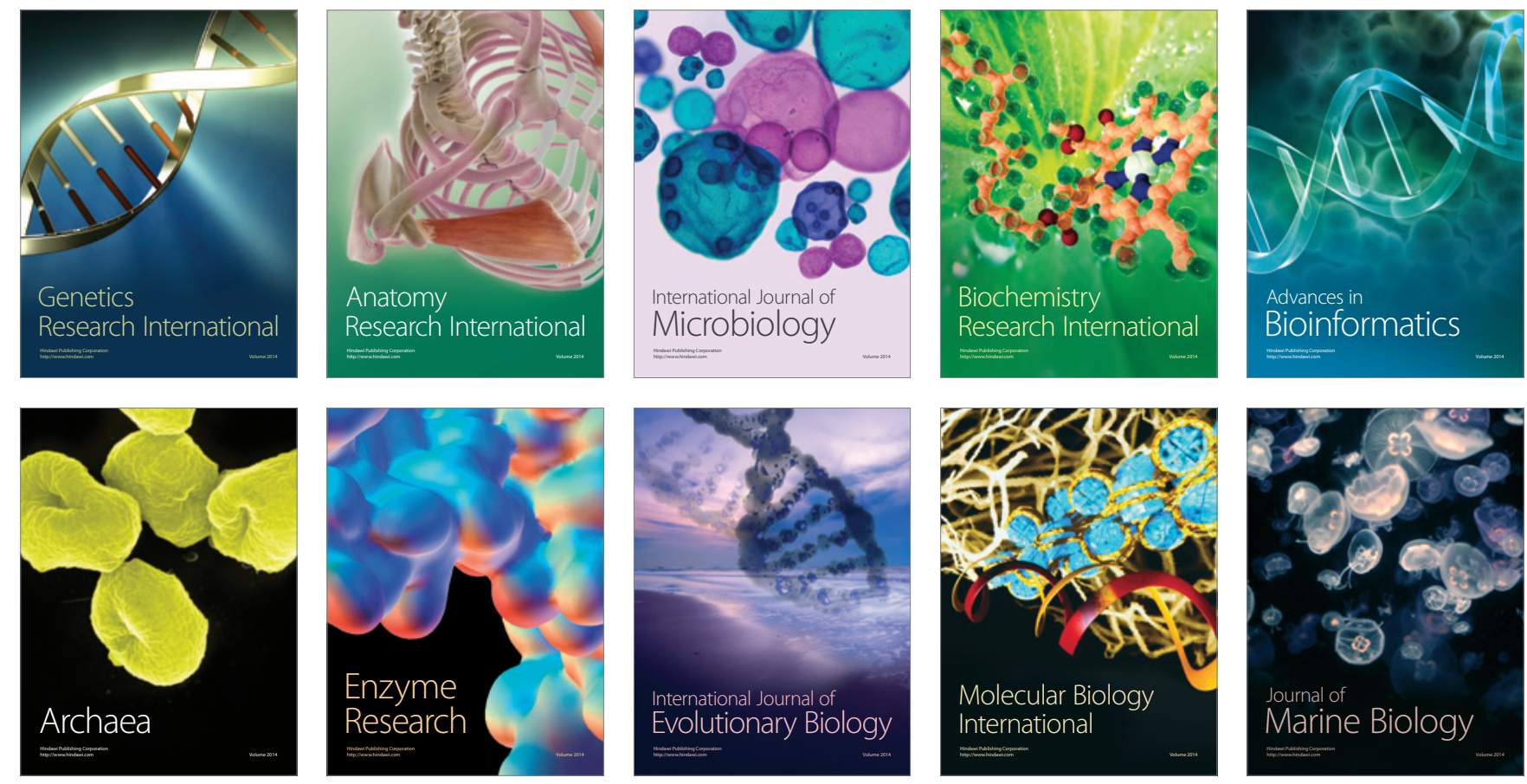